\title{
"Sand Bar" of Actinoid and Neighboring Elements in a Chart of Nuclides
}

\author{
Kenji Yoshihara and Tsutomu SekINE \\ Department of Chemistry, Faculty of Science, Tohoku University \\ Aoba, Aramaki, Sendai-shi 980 \\ Received December 4, 1981
}

\begin{abstract}
Inspection of a chart of nuclides reveals a "sand bar" of actinoid and neighboring elements when a suitable half-life level is chosen. A bay of $\alpha$-instability lying between the nuclides of neutron magic number 126 and the $\beta$-stability line in the actinoid group is a characteristic feature in this area. Calculation shows that fairly good agreement is obtained between the measured half-lives and those derived theoretically.
\end{abstract}

Key Words: stability of nuclides, half-life, actinoid, actinoid "sand bar", chart of nuclides

\section{Introduction}

Various kinds of charts of nuclides have been issued in order to give an overlook for a number of existing nuclides ${ }^{11}$. Usually an axis of neutron number of a nuclide is taken as an abscissa and that of proton number as an ordinate.

As is well known, stability of nuclides relates to the shell structure of a nucleus. The nucleus which has a magic number of neutrons and/or protons is especially stabilized. Representative examples of such nuclides are ${ }^{40} \mathrm{Ca}(Z=$ 20, $N=20),{ }^{58} \mathrm{Ni}(Z=28),{ }^{87} \mathrm{Rb}(N=50),{ }^{88} \mathrm{Sr}(N=$ 50), ${ }^{89} \mathrm{Y}(N=50),{ }^{90} \mathrm{Zr}(Z=50)$ and ${ }^{208} \mathrm{~Pb}(Z=82$, $N=126$ ), among which the first and last ones show outstanding stability characterized by double magic numbers.

Based on such consideration on nuclear stability the presence of islands of superheavy elements was predicted by nuclear chemists ${ }^{2)}$ on the extention of the stability line in the nuclear chart. The first island of superheavy elements is supposed to be located in the neighborhood of the site $(Z=114, N=184)$, and the second one near the site $(Z=164, N=318)$. According to their concept, stable nuclides with lower $Z$ numbers are expressed as a long peninsula which spans from hydrogen $(Z=1)$ to uranium $(Z=$ 92 ) in the "sea of instability".

\section{Results and Discussion}

2.1 Investigation of the sand bar in the chart of nuclides

Recently, we have found an interesting structure of this peninsula. In Fig. 1, where the nuclides described in the "Table of Isotopes"3) are shown in squares open or closed corresponding to unstable or stable ones, the peninsula is cleary divided into two parts: a main part and a small part with a mass $A \geqq 218$. In this case nuclides with half-life below $1 \mathrm{sec}$ are omitted. If no selection of half-life is done, separation of the main part and the tip will disappear, as in the ordinary chart of nuclides.

The group of the nuclides with $A \geqq 218$ in Fig. 1 may be compared to a "sand bar" which is connected with peninsula in a low tide and is separated in a high tide. When the half-life limit for selection of the nuclides is lowered, for

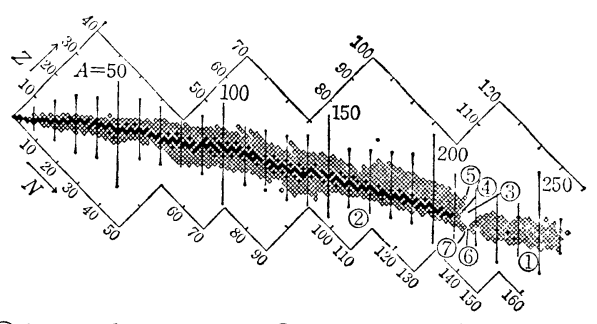

(1)Actinoid sand bar, (2)Main land, (3)Bay of $\alpha$ instability, (4)Deep of $\alpha$-instability, (5Cape of neutron magic number 126-1, (6) Polonium strait, (7) Cape of proton magic number 82

Fig. 1 Chart of nuclides with half-life over $1 \mathrm{sec}$. 
example, to the level $10^{-7} \mathrm{sec}$, no separation will be observed. If the limit is raised to the level of $10^{8}$ years, the sand bar will sink under the sea with three exceptional nuclides ${ }^{232} \mathrm{Th},{ }^{235} \mathrm{U}$ and ${ }^{238} U$ (hatched squares) which may be compared to the rock in the central part of the sand bar.

2.2 Detailed features in the vicinity of the "actinoid sand bar"

In order to indicate the presence of the "actinoid sand bar" unambigueously, it is recommendable to describe detailed features of the vicinity of the sand bar involving the "bay of $\alpha$ instability" and the "polonium strait". If one wishes to approach to this problem, at least two points should be clarified: one is to find a reasonable basis of the presence of minina of halflives in a series of isotopes having the same atomic number $Z$ in the neighborhood of the sand bar, and the other is to find also a minimum in a series of elements with masses $A_{s}$ on the stability line of nuclides.

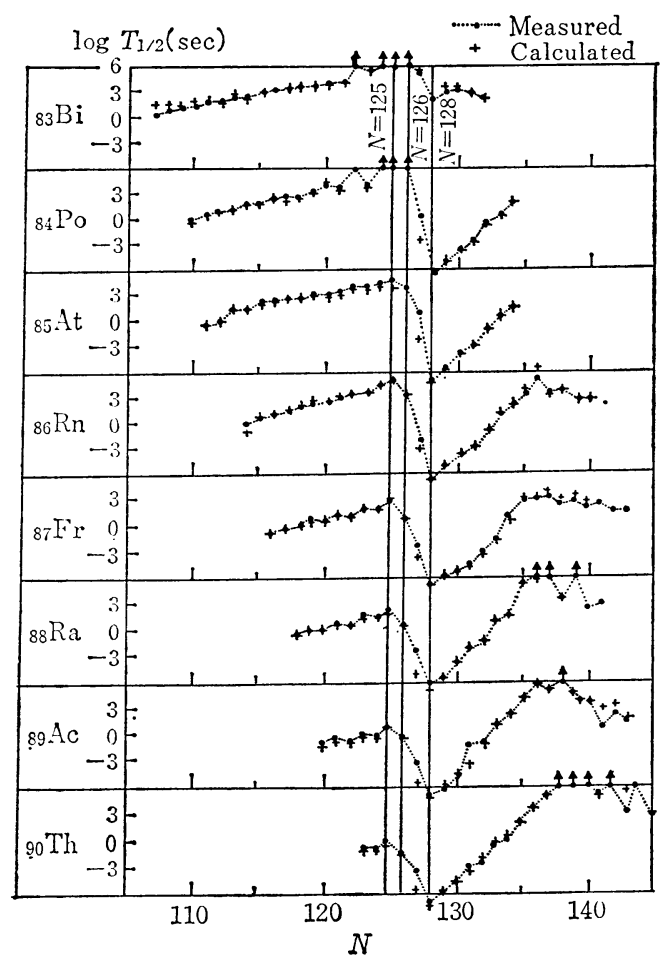

Fig. 2 Half-lives of preactinoid and actinoid nuclides in the neighborhood of the "bay of $\alpha$-instability".
The half-lives in a logarithmic scale of the isotopes with $Z$ ranging from $83(\mathrm{Bi})$ to $90(\mathrm{Th})$ are plotted against neutron number $N$ in Fig. 2 . The closed circles show the experimental data taken from the "Table of Isotopes" (1978) and the crosses show the values calculated from the theory of $\alpha$-decay ${ }^{4)}$ and the gross theory of $\beta$ stability ${ }^{5}$. The nuclides which are located in the bay of $\alpha$-instability have strong tendency to emit $\alpha$-particles. Systematics of $\alpha$-decay energy were extensively studied by Wapstra, et $\mathrm{al}^{6)}$. Half-lives of the isotopes $\left(T_{1 / 2}\right)$ can be calculated using the $\alpha$-decay energy described by Wapstra, et al., according to the following relations.

$$
\begin{aligned}
& T_{1 / 2}=\frac{0.693}{\omega \exp (-x)}, \\
& x= 2(2 m)^{1 / 2} \cdot 2 \pi / h \cdot \frac{2 Z e^{2}}{E^{1 / 2}} \\
& \times\left[\arccos y^{1 / 2}-y^{1 / 2}(1-y)^{1 / 2}\right], \\
& y=E a / 2 Z e^{2},
\end{aligned}
$$

were $\omega$ is the frequency with which the $\alpha$ particle present at the barrier and $m$ is the reduced mass of the $\alpha$-particle, $h$ is the Planck's constant, $e$ is the electron charge, $E$ is $\alpha$-decay energy, and $a$ is the effective nuclear radius.

For the $\beta$-decay and EC decay cases calculation is made by the gross theory proposed by Yamada, et $a .^{5}$, and corrections are applied to the nuclides having mixture of $\alpha$-decay and EC decay.

As shown in Fig. 2 experimental data agree with calculated ones. A minimum of the halflife appears at the neutron number 128 which corresponds to the excess of two neutrons for the magic number 126. It is interesting to see the first peak of the half-life appears at the neutron number 125 which is the neutron magic number 126 minus one. The reason why the nuclides having 125 neutrons are more stable than those having magic number neutrons probably relates to the difficulty of emission of $\alpha$ particles from the nucleus by neutron-neutron combination in an odd neutron nuclide compared to an even neutron nuclide in this region. Thus a cape of neutron magic number 126 minus 1 appears in Fig. 1.

Next we will consider the scission of the stability line by the "polonium strait" in Fig. 1 . The $\beta$-stability line is calculated by the following formula. 


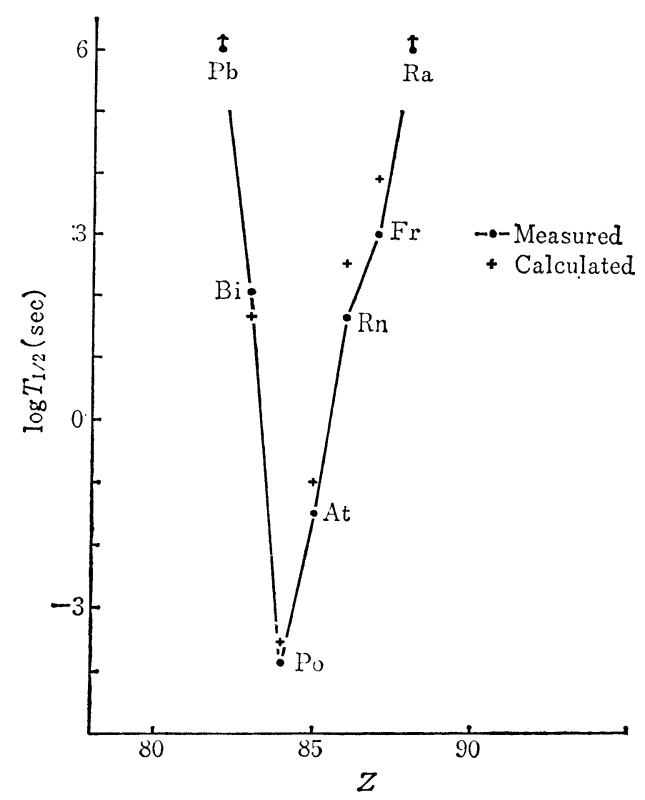

Fig. 3 Half-lives of preactinoid and actinoid elements on the $\beta$-stability line.

$$
Z=a A /\left(2.02+0.015 A^{2 / 3}\right)+\delta,
$$

where $Z$ is an atomic number, $A$ is an atomic mass, and $a$ and $\delta$ are the parameters ajusting the line. We have found that $a=1$ and $\delta=0.32$ are best fit in the region $Z=82$ to 92 for calculation. For even and odd $Z$ numbers, parameters of different size are usually employed, but the use of a single set of parameters is recommended taking representatives of the even nuclides in this case, because we are confronted in the problem of the scission of the stability line.

In Fig. 3, the half-life is plotted to the atomic number of the nuclides on the stability line. This also has a deep valley of half-life ex- ceedingly below $1 \mathrm{sec}$ in the region of Po which corresponds two proton excess compared to the proton magic number 82 .

The above results strongly support the presence of the "actinoid sand bar" in the neighborhood of actinoid elements with $A \geqq 218$.

Even if the data in the "Chart of the Nuclides 1980"1) which contains theoretically predicted nuclides are adopted, general tendency is unaltered except that the level of the half-life is set somewhat longer.

\section{References}

1) For example, W. Seelmann-Eggebert, G. Pfenning and H. Münzel: "Nuklidkarte", 4th ed., Kernforschungszentrum, Karlsruhe (1974); "Chart of Nuclides", 11 ed. Knolls Atomic Power Lab., G.E. Co., Schenectady, New York, (1972); Y. Yoshizawa, et al.: "Chart of the Nuclides 1980" NEANDC (J)-70/U Japan Atomic Energy Research Institute (1980)

2) G.T. Seaborg: "The Transuranium Elements", p. 5, Mendeleev Centennial, Houston (1969)

3) C.M. Lederer and V.S. Shirley (ed.): "Table of Isotopes", 7th ed. John Wiley \& Sons, Inc., New York (1978)

4) G. Gamow: Z. Physik, 51, 204 (1928); R. W. Gurney and E.U. Condon: Nature, 122, 439 (1928)

5) K. Takahashi, M. Yamada and T. Kondoh: Atomic Data and Nuclear Data Tables, 12, 101 (1973)

6) A.H. Wapstra and K. Bos: ibid., 19, 175 (1977) 
要旨

\title{
核種図表上のアクチノイドおよび近接元素の砂州について
}

\author{
吉原賢二, 関根 勉 \\ 東北大学理学部化学科 \\ 980 仙台市荒卷字青葉
}

核種図表をくわしく見れば，適当な半減期レベルを設定するとき，フクチノイドと近接元素の 「砂州」があることが分かる。中性子魔術数126の核種とフクチノイドグループの中の $\beta$ 安定線の間 に $\alpha$ 不安定性の湾があり,これがこの領域の特徴をなしている。計算上実測された半減期と理論的 に導かれた半減期との間にかなりよい一致が見出される。 